\title{
DINAMIKA ELEKTORAL YANG MEMPENGARUHI MASYARAKAT DUSUN KIMARAGANG DI DUN TANDEK DALAM PILIHAN RAYA DUN SABAH PADA ERA UNITED SABAH NATIONAL ORGANISATION (USNO) DAN PARTI BERSATU RAKYAT JELATA SABAH (BERJAYA): 1967 - 1982 Electoral Dynamics Influencing the Kimaragang Dusun Community of Tandek Constituency in Sabah State Elections During the Era of the United Sabah National Organisation (USNO) and Parti Bersatu Rakyat Jelata Sabah (BERJAYA): 1967 - 1982
}

\author{
${ }^{1}$ MANUAL DAMILAN \\ ${ }^{2}$ LAI YEW MENG \\ ${ }^{3}$ MAUREEN DE SILVA
${ }^{1 £ 3}$ Program Sejarah, Fakulti Kemanusiaan, Seni dan Warisan, Jalan UMS, Universiti Malaysia Sabah, Kota Kinabalu, Sabah. Diterima: 9 Feb 2018 / Dibaiki: 24 Mei 2018 \\ manualdamilan@gmail.com,laiyewmeng@yahoo.com,mds_asoka@yahoo.com
}

\begin{abstract}
Abstrak Artikel ini membincangkan dinamika elektoral yang mempengaruhi gelombang sentimen dan pilihan politik masyarakat Dusun Kimaragang semasa Pilihan Raya DUN Sabah 1967 hingga 1982, iaitu semasa era pentadbiran United Sabah National Organisation (USNO) dan Parti Bersatu Rakyat Jelata Sabah (BERJAYA). Ramai penulis dan pengkaji mendakwa bahawa senario politik Malaysia khususnya di Sabah sejak dahulu adalah berasaskan dinamika primordial, iaitu sentimen kuat yang tidak dapat dielakkan dan berkait dengan persamaan ciri sosial manusia seperti agama, etnik, puak, bahasa, kekeluargaan dan sebagainya (Loh, 2009; xii). Senario ini telah menyebabkan kebanyakan parti politik cenderung meletakkan calon yang memiliki banyak persamaan dari segi etnik dan agama dengan pengundi di satu-satu kawasan. Walaupun begitu, kemenangan calon bukan Kimaragang (Pilihan Raya 1967 dan 1981) dan kemenangan calon beragama Islam pada tahun 1971 dan 1982 di kawasan Tandek membuktikan bahawa dinamika primordial bukanlah satu-satunya dinamika yang mempengaruhi sentimen dan keputusan politik masyarakat Dusun Kimaragang. Sebaliknya, terdapat juga dinamika-dinamika lain yang turut terlibat. Justeru, berpandukan kepada pendekatan kualitatif, kajian akan melihat sejauhmana dinamika primordial mempengaruhi sentimen
\end{abstract}


politik masyarakat Dusun Kimaragang di kawasan DUN Tandek dari tahun 1967 hingga 1982.

Kata kunci: Dinamika elektoral, Pilihan Raya DUN Sabah, DUN Tandek, sejarah politik Sabah, masyarakat Dusun Kimaragang, Kota Marudu.

Abstract This article discusses the electoral dynamics affecting the popular groundswell and political choice of the Kimaragang Dusun community in Sabah State Assembly elections from 1967 to 1982, notably during the era of the United Sabah National Organisation (USNO) and Parti Bersatu Rakyat Jelata Sabah (BERJAYA) administration. Many writers and researchers claim that Malaysia's political scenario especially in Sabah has been primarily driven by primordial dynamics which refers to strong sentiments related to human social characteristics such as religion, ethnicity, language, family, and so on (Loh, 2009, p. xii). This scenario has created a tendency among many political parties to place candidates who share common ethnic and religious attributes with the majority of voters in one area. However, the victory of non-Kimaragang candidates (1967 and 1981 State Election) as well as Muslim candidates in 1971 and 1982 in the predominantly Dusun Kimaragang area of Tandek proved that primordial sentiments were not the only electoral dynamic affecting the popular groundswell and political decisions of the Kimaragang Dusun community as there were also other dynamics involved. Hence, based on a qualitative approach, the study seeks to analyse the extent to which primordial dynamics influenced the political sentiments of the Kimaragang Dusun community in the Tandek state constituency from 1967 to 1982.

Keywords: Electoral dynamics, Sabah State Assembly election, Tandek State Constituency, Sabah political history, Dusun Kimaragang community, Kota Marudu.

\section{PENDAHULUAN}

Dinamika elektoral dikaitkan dengan pilihan raya biasanya merupakan fungsi interaksi antara pemimpin politik dan pengundi, serta faktor endogen 
dan eksogen yang mempengaruhi persepsi dan matlamat pengundi (Asmeret Michele, George \& Richard, 2010; 1). Ringkasnya, dinamika elektoral adalah faktor yang mampu mempengaruhi sentimen dan keputusan politik pengundi, antaranya adalah seperti dinamika primordial, tadbir urus, patronclient, politik pembangunan dan sebagainya.

Masyarakat Dusun Kimaragang kebanyakannya tinggal di kawasan Dewan Undangan Negeri (DUN) Tandek yang terletak dalam kawasan Parlimen Kota Marudu. Masyarakat ini tertumpu di beberapa buah kampung antaranya adalah seperti Kampung Liabas, Tondig, Togudon, Samparita, Tinogu, Tinangkaban, Tingkalanon, Morion, Batition, Nolotan, Salimandut, Singgamata, Minitampak, Longob, Mosolog, Damai, Gana, Sumbilingon, Garuda, dan Kampung Rasak Darat (Jonan Gaul, 2017). Masyarakat Dusun Kimaragang adalah subetnik Kadazandusun yang terbesar di Kota Marudu (Arnold Puyok, 2014, p. 185). Senario ini memberi kelebihan kepada masyarakat ini bertindak sebagai kingmaker, khususnya untuk membuat keputusan di DUN Tandek sendiri.

Sejarah penglibatan masyarakat Dusun Kimaragang dalam politik Sabah telah bermula seawal sebelum pembentukan Malaysia. Hal ini dapat dilihat dalam pembabitan Hj. Abdul Jamal Ponggoron @ Jamari Ponggoron dan juga Supu Santiku yang bertarung sesama sendiri dalam pungutan suara bagi memilih wakil-wakil ke kuasa tempatan (Majlis Daerah). Keputusan pungutan suara itu telah memihak kepada Hj. Abdul Jamal Ponggoron yang seterusnya dilantik sebagai Native Chief di kawasan Kimaragang, iaitu di Tandek. Seterusnya, selepas pembentukan Malaysia, masyarakat Dusun Kimaragang meneruskan penglibatan mereka sama ada dalam politik pilihan raya mahupun politik kepartian khususnya di Kota Marudu. Ekoran daripada itu, semasa mentadbir Sabah, Kerajaan United Sabah National Organisation (USNO) telah memberikan kepercayaan kepada individu Kimaragang untuk mewakili Parlimen dan DUN di Sabah. Walau bagaimanapun, calon Kimaragang yang bertanding atas tiket USNO tidak berjaya merebut kerusi DUN Tandek semasa Pilihan Raya DUN pertama selepas pembentukan Malaysia iaitu pada tahun 1967. Semasa Pilihan Raya DUN tahun 1971 barulah calon Kimaragang mula menyandang kerusi DUN Tandek. Demikian juga semasa era pentadbiran Parti Bersatu Rakyat Jelata 
Sabah (BERJAYA) dan semasa era Parti Bersatu Sabah (PBS), iaitu calon Kimaragang masih juga menyandang kerusi tersebut.

\section{KAJIAN LEPAS}

Secara ringkasnya, kajian lepas yang memberi fokus kepada masyarakat Dusun Kimaragang dalam bidang politik kurang diketengahkan secara langsung. Oleh itu, kajian ini cuba mengetengahkan masyarakat Dusun Kimaragang sebagai subjek untuk menilai dinamika elektoral atau politik yang mempengaruhi mereka dalam pilihan raya. Terdapat beberapa jenis dinamika elektoral atau politik antaranya adalah seperti primordialisme (etno-agama), urus tadbir, sosioekonomi, dan personaliti calon. Dalam hal ini, Shafie Nor (1981) menyatakan penubuhan parti politik awal di Sabah adalah untuk mempertahankan ciri-ciri perkauman berlandaskan keturunan dan agama. Hal ini menurut Hamdan dan Mahat (2014) adalah kerana agama adalah sebagai salah satu alat politik. Puyok dan Bagang (2011) pula mengulas bahawa politik masyarakat Kadazandusun di Sabah dibentuk melalui sekurang-kurangnya tiga faktor iaitu identiti etnik, penyatuan budaya dan institusi kepimpinan Huguan Siou. Ho Hui Ling (2003) juga memberikan reaksi kepada pernyataan tersebut dengan menyatakan kemunculan United National Kadazan Organisation (UNKO) yang memfokuskan kepada bumiputera bukan Islam menimbulkan kebimbangan dalam kalangan masyarakat bumiputera Islam seterusnya menubuhkan USNO. Hal ini demikian kerana UNKO dipimpin oleh Donald Stephen yang pada masa itu beragama Kristian. Junaidi dan Mazlan (2014) dalam kajian pilihanraya di Kuala Lumpur menyatakan perkauman dan kewilayahan menjadi faktor utama dalam penentuan sokongan terhadap parti-parti yang bertanding. Mohd Fuad Mat Jali, Ahmad Nidzammudin dan Zaini (2005) pula menyatakan bahawa faktor etnik dan kawasan sebagai faktor yang mempengaruhi pemilihan parti politik di Malaysia, secara amnya.

Junaidi, Novel dan Mohd Azlan (2014), menyatakan bahawa parti politik yang memperjuangkan isu kemanusiaan seperti keadilan, ketelusan, anti rasuah dan hak asasi juga mampu mempengaruhi gelombang sentimen dan keputusan pengundi. Selain itu, Mohd Ali Kamaruddin dan Jamaie 
(2005) menyatakan budaya politik masyarakat Melayu telah berubah ekoran daripada faktor ekonomi yang membezakan antara kaum Melayu dengan bukan Melayu khususnya masyarakat Cina. Mohd Fuad Mat Jali et al. (2012) menghujahkan bahawa personaliti calon juga berpotensi dalam mempengaruhi gelombang sentimen dan keputusan politik.

\section{KAEDAH KAJIAN}

Kajian dilakukan dengan mengaplikasikan pendekatan kualitatif melalui kaedah kajian perpustakaan. Sumber-sumber primer seperti surat khabar Daily Express dan laporan-laporan keputusan Pilihan raya 1967 hingga 1982 dirujuk untuk mengumpulkan data berkaitan dengan statistik semasa pilihan raya bagi tahun-tahun yang terlibat dalam kajian ini. Sumber-sumber sekunder seperti buku, bab dalam buku dan artikel-artikel turut dirujuk untuk memandu analisis dalam kajian ini. Kajian yang dijalankan juga adalah berpaksikan kepada disiplin Sejarah di samping menggunakan pendekatan sains politik sebagai ilmu bantu dalam kajian ini. Selain itu, pengumpulan data melalui temu bual juga turut terlibat dalam kajian ini. Beberapa individu terpilih dalam masyarakat Dusun Kimaragang yang pernah terlibat secara langsung dalam politik dari tahun 1967 hingga 1982 ditemu bual. Antara mereka adalah Majawab Masantun (calon BERJAYA Pilihan raya DUN Sabah 1986), Unggas Bodok (Mantan Ketua Pemuda USNO Bahagian Bandau 1972 - 1976) dan Saibon Papalan (calon BEBAS Pilihan Raya Kecil DUN Tandek 1982). Hal ini dilakukan bagi mendapatkan gambaran dalam perspektif masyarakat Dusun Kimaragang berkenaan dengan senario politik masyarakat tersebut yang seterusnya akan membantu pengkaji untuk mengesan dinamika elektoral atau politik yang mempengaruhi masyarakat Dusun Kimaragang dalam tahun 1967 hingga 1982.

\section{PERBINCANGAN/DAPATAN KAJIAN}

Dinamika elektoral atau dinamika politik bukanlah sesuatu yang dapat dilihat dengan pandangan mata kasar. Dalam kajian ini, dinamika elektoral atau politik diteliti daripada perspektif sejarah dengan melihat laporan 
pilihan raya tahun 1967 hingga tahun 1985 (Jadual 1). Berdasarkan kepada laporan tersebut, seterusnya analisis ke atas individu yang memenangi satusatu edisi pilihan raya akan dijalankan di samping meneliti faktor dalaman dan luaran yang mempengaruhi kemenangan calon tersebut. Melalui analisis yang dilakukan, maka secara langsung dinamika elektoral atau politik yang terlibat akan dapat dikenal pasti.

\section{Pilihan Raya di DUN Tandek 1967 - 1982}

Sejak kawasan Dewan Undangan Negeri (DUN) Tandek diwujudkan, kawasan DUN tersebut diwakili oleh Datuk Herman J. Luping bermula tahun 1967 hingga tahun 1971. Herman Luping diletakkan sebagai calon UPKO di DUN Tandek menentang calon USNO Madina Unggut, anak tempatan Tandek dari etnik Dusun Kimaragang. Apabila keputusan diumumkan kemenangan berpihak kepada Herman Luping dengan undi sebanyak 2,207 berbanding Madina Unggut yang hanya memperoleh 690 undi (Daily Express, 28 April 1967). Majoriti undi adalah sebanyak 1,517 undi. Seterusnya pada tahun 1971, DUN Tandek mulai diwakili oleh masyarakat Dusun Kimaragang. Majuning Majun adalah wakil di kawasan Tandek bermula pada tahun 1971 hingga tahun 1976 selepas beliau menang tanpa bertanding pada Pilihan Raya DUN 1971. Majuning Majun hanya menduduki kerusi DUN Tandek selama satu penggal dan selepas itu, Parti BERJAYA mengambil alih pentadbiran Sabah dan kerusi di DUN Tandek.

Tahun 1976 menyaksikan BERJAYA telah meraih kemenangan dalam Pilihan Raya DUN Sabah. BERJAYA memenangi 28 daripada 48 kerusi yang dipertandingkan berbanding USNO yang hanya mendapatkan 20 kerusi (Sabihah Osman, 2008, p. 15). Pilihan Raya DUN Sabah tahun 1976 menyaksikan “Kimaragang Derby", iaitu pertarungan empat penjuru antara sesama Kimaragang di DUN Tandek. Vilson U. Malingka berdepan dengan Haji Omar Majun (USNO), Albert Surubi Adun (Pekemas), dan Baudi Unggut (BEBAS) (Daily Express, 15 April 1976). Kemenangan akhirnya berpihak kepada calon BERJAYA, Vilson U. Malingka dengan undi sebanyak 1,437 manakala pesaing terdekatnya iaitu Haji Omar Majun mendapat 1,103 undi beza 334 undi (Daily Express, 15 April 1976). Dua calon lain, iaitu Albert Surubi Adun dan Baudi Unggut hilang wang pertaruhan 
apabila masing-masing mendapat 65 dan 159 undi (Daily Express, 15 April 1976). Seterusnya, Vilson U. Malingka tidak bertanding pada Pilihan Raya DUN Sabah tahun 1981 kerana pucuk pimpinan BERJAYA memilih Dason Gaban sebagai calon BERJAYA di DUN Tandek. Tambahan pula, Vilson U. Malingka telah mendapat kepercayaan baharu, iaitu menjadi Pengerusi Ko-Nelayan untuk daerah Bandau (Majawab Masantun, 2017). Di samping itu, ADUN Lantikan iaitu Albert Surubi Adun mencadang serta menyokong pencalonan Dason Gaban (Majawab Masantun, 2017).

Walaupun Dason Gaban bukan anak tempatan di Tandek, beliau tetap memenangi kerusi DUN Tandek atas tiket BERJAYA selepas menewaskan Zulkifle Majun@ Maralang (USNO) dan Masingkan bin Masampun (Pasok) (Laporan Pilihanraya DUN Sabah, 1981). Namun begitu, atas faktorfaktor politik di DUN Tandek pada masa itu, pilihan raya kecil terpaksa diadakan pada tahun 1982 apabila Dason Gaban telah diberhentikan oleh pucuk pimpinan parti BERJAYA sebagai wakil rakyat DUN dan dilantik sebagai Setiausaha Politik kepada Datuk Hj. Mohd. Noor Hj. Mansoor, iaitu Menteri Pembangunan dan Perancangan Kewangan Sabah (The New Sabah Times, 14 Ogos 1982). Rentetan daripada itu, sekali lagi telah berlaku "Kimaragang Derby" di DUN Tandek bagi mengisi kekosongan wakil rakyat di kawasan DUN tersebut. Pertandingan tiga penjuru antara Vilson U. Malingka (BERJAYA), Dominik Gorotom (BEBAS) dan Saibon Papalan (BEBAS) akhirnya telah memihak kepada Vilson U. Malingka (The New Sabah Times, 15 September 1982). Kerusi tersebut kembali semula kepada Vilson pada tahun 1982 sehingga kejatuhan BERJAYA pada tahun 1985. Pilihan raya DUN Sabah 1985 menyaksikan kemenangan calon PBS di DUN Tandek iaitu Datuk Saibul Supu. Penyandang kerusi DUN Tandek iaitu Vilson Uhot@ Herowan Malingka (BERJAYA) telah tewas bersama dengan dua orang lagi calon iaitu Kee Abdul Jalil Abdullah (USNO) dan Henry Bungas (PASOK). Kekalahan BERJAYA dalam Pilihan Raya tersebut menandakan tamatnya era pentadbiran BERJAYA yang bermula pada tahun 1976. Ringkasan berkenaan dengan Pilihan Raya DUN Sabah 1967 hingga 1982 dipaparkan dalam Jadual 1. 
Jadual 1 Senarai calon bertanding dalam Pilihan Raya DUN Tandek 1967 $-1982$

\begin{tabular}{|c|c|c|c|c|c|}
\hline Tahun & Calon & Etnik & Undi & Menang & Majoriti \\
\hline \multirow{2}{*}{1967} & Herman Luping (UPKO) & Dusun Penampang & 2,207 & \multirow{2}{*}{ Herman Luping } & \multirow{2}{*}{1,517 undi } \\
\hline & Madina Unggut (USNO) & Dusun Kimaragang & 609 & & \\
\hline 1971 & Majuning Majun (USNO) & Dusun Kimaragang & MTB & Majuning Majun & MTB \\
\hline \multirow{4}{*}{1976} & $\begin{array}{l}\text { Vilson Uhot Malinglka } \\
\text { (BERJAYA) }\end{array}$ & Dusun Kimaragang & 1,437 & \multirow{4}{*}{$\begin{array}{l}\text { Vilson Uhot } \\
\text { Malinglka }\end{array}$} & \multirow{4}{*}{110 undi } \\
\hline & $\begin{array}{l}\text { Majuning Majun@ Haji Omar } \\
\text { (USNO) }\end{array}$ & Dusun Kimaragang & 1,103 & & \\
\hline & Albert Surubi Adun (Pekemas) & Dusun Kimaragang & 65 & & \\
\hline & Baudi Unggut (BEBAS) & Dusun Kimaragang & 159 & & \\
\hline \multirow{3}{*}{1981} & Dason Gaban (BERJAYA) & Dusun & 1,504 & \multirow{3}{*}{ Dason Gaban } & \multirow{3}{*}{700 undi } \\
\hline & $\begin{array}{l}\text { Zulkifli Majun@ Maralang } \\
\text { (USNO) }\end{array}$ & Dusun Kimaragang & 804 & & \\
\hline & $\begin{array}{l}\text { Masingkan@ Shingkan } \\
\text { Masumpun (Pasok) }\end{array}$ & Dusun Kimaragang & 666 & & \\
\hline \multirow{3}{*}{1982} & $\begin{array}{l}\text { Vilson Uhot Malingka @ } \\
\text { Herowan (BERJAYA) }\end{array}$ & Dusun Kimaragang & 1,330 & \multirow{3}{*}{$\begin{array}{c}\text { Vilson Uhot } \\
\text { Malingka @ } \\
\text { Herowan }\end{array}$} & \multirow{3}{*}{87 undi } \\
\hline & Dominik Gorotom (BEBAS) & Dusun Kimaragang & 1,243 & & \\
\hline & Saibon Papalan (BEBAS) & Dusun Kimaragang & 413 & & \\
\hline
\end{tabular}

Sumber: Daily Express 28 April 1967

Daily Express 15 April 1976

Laporan Pilihan raya DUN Sabah 1981, SPR

The New Sabah Times, 15 September 1982

http://semak.spr.gov.my/spr/laporan/5_KedudukanAkhir.php

\section{Dinamika Elektoral}

Lazimnya, dalam beberapa edisi pilihan raya di Sabah sejak tahun 1967, kebanyakan pengundi di Sabah cenderung dipengaruhi oleh dinamika primordial, iaitu kecenderungan memilih calon berdasarkan kepada etnik dan agama. Penubuhan parti-parti politik pada peringkat awalnya juga bertitik tolak daripada keutamaan etnik dan agama. Shafie Nor (1981) turut menyokong senario ini bila menyatakan penubuhan parti politik di Sabah dahulu adalah untuk mempertahankan ciri-ciri perkauman berlandaskan keturunan dan agama (Shafie Nor, 1981, p. 3). Ho Hui Ling (2003) pula menyatakan kemunculan UNKO (seterusnya bertukar nama kepada United 
Pasok Momogun Kadazan Organisation (UPKO) selepas bergabung dengan parti Pasok Momogun pada tahun 1964) yang lebih kepada bumiputera bukan Islam menimbulkan kebimbangan dalam kalangan masyarakat bumiputera Islam seterusnya menubuhkan USNO (Ho Hui Ling, 2003, p. 65). Pendapat sama turut dinyatakan oleh Sabihah Osman (2008); tindak-tanduk USNO lebih menekankan kepentingan bumiputera Islam (Sabihah Osman, 2008, p. 10).

Kenyataan tersebut jelas menunjukkan bahawa pendapat umum kebanyakan penulis menyimpulkan bahawa masyarakat di Sabah semasa era USNO mahupun BERJAYA cenderung berpaksikan kepada unsur-unsur primordial sebagai penentu dalam membuat keputusan politik, khususnya pemilihan calon perwakilan di kawasan mereka. Hal ini dapat dilihat pada siri pilihan raya DUN Sabah 1967 di DUN Tandek yang menyaksikan kemenangan berpihak kepada Herman Luping dari UPKO menewaskan Madina Unggut dari USNO (Jadual 1). Dinamika primordial dalam aspek etnik Dusun bukanlah sesuatu yang dominan dalam mempengaruhi keputusan politik masyarakat Dusun Kimaragang. Mereka lebih dipengaruhi oleh parti politik yang bertanding di DUN Tandek iaitu UPKO dan juga USNO. Walaupun begitu, aspek agama setiap parti itu lebih dominan dalam menyebabkan masyarakat Dusun Kimaragang lebih memihak kepada UPKO. Secara teknikalnya, Madina Unggut sepatutnya memenangi kerusi DUN Tandek kerana beliau adalah anak tempatan di DUN tersebut. Walaupun begitu, beliau tewas kerana bertanding di bawah tiket USNO yang didakwa oleh sebahagian besar masyarakat Dusun Kimaragang sebagai parti Islam. Senario tersebut juga bertepatan dengan pernyataan Hamdan Aziz yang menyatakan sebahagian besar masyarakat Kadazandusun menganggap USNO sebagai parti Islam (Hamdan Aziz, 2015, p. 118).

Dalam Pilihan Raya DUN Sabah tahun 1971 pula menyaksikan kemenangan berpihak kepada USNO dengan memenangi 28 kerusi DUN Sabah yang kebanyakannya diperoleh secara tanpa bertanding. Sabah Chinese Association (SCA) yang juga rakan sekutunya pula memperoleh empat kerusi. Senario ini berlaku ekoran pembubaran UPKO yang seterusnya menjadikan USNO menjadi parti tunggal yang berpengaruh di Sabah. Justeru, Tun Mustapha dikatakan telah membuat pertemuan dengan Majuning Majun untuk menawarkannya menjadi wakil rakyat DUN Tandek 
dengan syarat beliau perlu menyertai USNO (Majuning Majun, 2016). Hal ini menyebabkan dinamika yang mempengaruhi masyarakat Dusun Kimaragang juga tidak jelas ekoran kerusi DUN Tandek dimenangi secara tanpa bertanding melalui Majuning Majun.

Semasa era BERJAYA, dinamika elektoral atau politik khususnya di DUN Tandek tidak jauh bezanya semasa era USNO. Pemilihan perwakilan lebih cenderung dipengaruhi oleh parti politik yang bertanding. Dalam konteks Sabah, BERJAYA adalah sebuah parti campuran antara bumiputera Islam dengan bukan Islam. Ekoran daripada itu, sokongan bumiputera bukan Islam khususnya masyarakat Dusun Kimaragang ditumpukan kepada BERJAYA semasa dua siri pilihan raya DUN dan satu Pilihan Raya kecil di DUN Tandek.

Semasa peringkat awal kewujudan BERJAYA, masyarakat Dusun Kimaragang mendakwa bahawa parti tersebut adalah parti bumiputera bukan Islam kerana presidennya adalah Donald Stephens (Tun Fuad Stephens). Walhal, parti tersebut sebenarnya berkonsepkan multi-racial party. Senario tersebut telah mendedahkan persepsi yang baik daripada masyarakat Dusun Kimaragang terhadap BERJAYA. Tidak dinafikan bahawa senario ini telah menyebabkan pilihan raya DUN Sabah tahun 1976 telah memihak kepada BERJAYA khususnya di kerusi DUN Tandek. USNO pula ditolak disebabkan isu kepimpinannya yang lemah serta bersifat autokratik (Clarence D. Bongkos Malakun, 1981, p. 154). Sebagai contoh, penduduk Kimaragang yang didapati berambut panjang akan dipotong rambutnya serta-merta walaupun di hadapan orang ramai (Unggas Bodok, 2017). Polisi ini dijalankan selaras dengan polisi USNO dalam menghalang merebaknya budaya hippies dalam kalangan penduduk Sabah (Hamdan Aziz, 2015, p. 299). Berpunca daripada itulah masyarakat Dusun Kimaragang menuntut sebuah pentadbiran yang telus dan adil di Sabah. Di samping dinamika primordial, kemenangan BERJAYA pada tahun 1976 juga adalah orientasi rakyat Sabah yang inginkan pentadbiran bersifat good governance di Sabah, iaitu pentadbiran yang telus dan adil tanpa unsur-unsur politik kuku besi. Ringkasnya, pilihan raya DUN 1976 memperlihatkan dinamika good governance serta dinamika primordial telah mempengaruhi gelombang sentimen dan keputusan politik masyarakat Dusun Kimaragang. 
Selepas BERJAYA mengambil alih tampuk pentadbiran negeri, pembangunan berjalan lebih lancar dan dilaksanakan di Sabah khususnya di DUN Tandek ekoran jumlah peruntukan pembangunan daripada Kerajaan Pusat disalurkan secara konsisten, hasil daripada hubungan yang baik antara kerajaan BERJAYA dengan Kerajaan Persekutuan. Pembinaan jalan raya, jambatan-jambatan, rumah panjang, Pekan Tandek, SMK Tandek dan sebagainya telah dirancang dan dilaksanakan (The Sabah Times, 11 Januari 1983). Peningkatan jumlah peruntukan keseluruhan untuk daerah Bandau (Kota Marudu pada masa ini) juga mengalami peningkatan ketara, iaitu jumlah peruntukan pada tahun 1976 yang hanya berjumlah RM 273,170.00 telah meningkat kepada RM 1,827,740.00 pada tahun 1983 (ANS Fail 30/ $\mathrm{JKM} / \mathrm{PDKM} / 121 / 90 / \mathrm{BOX}$ 1). Jumlah tersebut menunjukkan pembangunan sedang serius dijalankan di daerah Bandau khususnya di DUN Tandek. Senario ini meletakkan BERJAYA sebagai sebuah kerajaan yang dilihat telah membawa pembangunan ekonomi dan insfrastruktur kepada Sabah khususnya DUN Tandek.

Lantaran itu, keputusan pilihan raya DUN 1981 serta pilihan raya kecil DUN Tandek 1982 telah menjadi manifestasi sokongan penduduk kepada polisi pembangunan yang dibawa oleh BERJAYA lantas menyebabkan populariti parti tersebut telah mengatasi populariti calon yang bertanding. Dalam hal ini dapat dilihat BERJAYA pada tahun 1981, iaitu Dason Gaban bukanlah anak tempatan DUN Tandek namun beliau menang atas kapasiti sebagai calon BERJAYA. Demikian juga halnya dengan Vilson Uhot Malingka@ Herowan yang masih memenangi kerusi DUN Tandek pada tahun 1982 walaupun beliau didakwa terlibat dalam isu personaliti. Isu personaliti yang dimaksudkan ialah beliau telah didakwa sanggup memeluk agama Islam demi kembali menjadi wakil rakyat di DUN Tandek (Majawab Masantun, 2017).

\section{KESIMPULAN}

Perkembangan politik di Sabah yang bertitik tolak daripada cadangan pembentukan Malaysia telah mewujudkan parti-parti politik. Fenomena ini telah mendorong Sabah ke arah berkerajaan sendiri yang seterusnya menggalakkan masyarakat Sabah dari pelbagai etnik untuk menceburkan 
diri dalam bidang politik di negeri ini. Melalui ruangan inilah masyarakat Dusun Kimaragang telah melibatkan diri dalam arena politik di Sabah. Di samping terlibat secara tidak langsung iaitu sebagai pengundi, masyarakat Dusun Kimaragang juga turut terlibat menjadi pemerintah iaitu sebagai wakil rakyat di kawasan Dusun Kimaragang iaitu di DUN Tandek.

Dinamika primordial sinonim dengan sentimen dan keputusan politik masyarakat Dusun Kimaragang khususnya pada tahun 1967. Dapat dilihat masyarakat Dusun Kimaragang adalah antara masyarakat yang dinamik dan mempunyai kematangan politik. Mereka tidak melihat calon Dusun Kimaragang yang bertanding itu sebagai suatu kewajipan untuk diundi dalam pilihan raya. Sebaliknya, mereka melihat dari pelbagai sudut dan tidak keterlaluan jika dikatakan bahawa masyarakat ini bersifat lebih terbuka dalam konteks etnik kerana tidak hanya bertindak berpaksikan komuniti etnik Dusun Kimaragang sahaja, tetapi bertindak sebagai masyarakat Dusun seluruh Sabah.

Selain dinamika primordial, dinamika tadbir urus atau good governance juga mempengaruhi sentimen politik masyarakat Dusun Kimaragang khususnya pada tahun 1976, iaitu semasa peralihan kuasa pentadbiran daripada USNO kepada BERJAYA. Di samping dinamika primordial dan tadbir urus, kemenangan BERJAYA juga adalah disebabkan oleh orientasi masyarakat Dusun Kimaragang untuk menumbangkan USNO di DUN Tandek. BERJAYA seterusnya merancang serta melaksanakan beberapa pembangunan di DUN Tandek sebagai "hadiah" kepada pengundi di kawasan tersebut sehinggakan mindset masyarakat Dusun Kimaragang yang majoriti di DUN tersebut meletakkan BERJAYA sebagai kerajaan yang boleh menjamin pembangunan DUN Tandek. Rentetan itu, pilihan raya yang seterusnya iaitu pada tahun 1981 dan pilihan raya kecil 1982 telah berpihak kepada BERJAYA yang telah berhasil menyebarkan hegemoninya kepada penduduk Sabah khususnya masyarakat Dusun Kimaragang. Sungguhpun begitu, kontroversi pentadbiran BERJAYA pada akhir penggal kedua pentadbirannya telah melemahkan parti tersebut sehingga akhirnya telah tewas kepada peneraju baharu kerajaan Sabah iaitu Parti Bersatu Sabah (PBS). 


\section{RUJUKAN}

ANS Fail 30/JKM/PDKM/121/90/BOX 1

Arnold Puyok \& Tony Paridi Bagang. (2011). Ethnicity, culture and indigenous leadership in modern politic: The case in Kadazandusun in Sabah, East Malaysia. Kajian Malaysia, 19, Supp. 1, 2011, 177-197.

Asmeret, B., Michael, B., George, B. \& Richard, H. (2010). Political dynamic determined between interactions between political leaders and voters. Kertas Kerja. 28th International Conference of The System Dynamics Society July 25-29, 2010. Sandia National Laboratories.

Buku Cenderamata 25 Tahun Sabah Merdeka Peringkat Daerah Kota Marudu. (1989). Jawatankuasa Kecil Publisiti dan Siaraya.

Daily Express, 28 April 1967.

Daily Express, 15 April 1976.

Hamdan Aziz. (2015). USNO dan BERJAYA politik Sabah. Kuala Lumpur. Dewan Bahasa dan Pustaka.

Hamdan Hj. Adnan \& Mahat Jamal. (2014). Pilihan raya umum di Sabah: Faktorfaktor penentuan kemenangan di Sabah. Jurnal Komunikasi Borneo, 1, 63.

Ho Hui Ling. (2003). Gagasan Malaysia: Satu kajian mengenai peranannya terhadap perkembangan parti politik di Sabah, 1961-1963. Prosiding Seminar Kebangsaan Pembinaan nasion Malaysia 2003. Pusat Penataraan Ilmu dan Bahasa, Universiti Malaysia Sabah

Jonan Gaul. 58. Ketua Anak Negeri, Mahkamah Anak Negeri Kota Marudu. Temu bual. 19 Oktober 2017.

Junaidi Awang Besar \& Mazlan Ali. (2014). Dari Barisan ke Pakatan: Berubahnya Dinamika Pilihanraya Umum Kuala Lumpur 1955-2013. Malaysia Journal of Society and Space, 10, 83-98.

Junaidi Awang Besar, Novel, Lyndon \& Mohd Azlan Abdullah. (2014). Politik pilihan raya dan partisipasi politik orang Ulu di Sarawak. Malaysia Journal of Society and Space, 10 (5) 135-147.

Laporan Pilihanraya DUN Sabah 1981, Suruhajaya Pilihan Raya.

Majawab Masantun. 58 Tahun. Calon BERJAYA Pilihan raya DUN Sabah 1986. Kampung Morion. Temu bual 10 Jun 2017.

Majuning Majun@Hj. Omar.80 tahun. Mantan Wakil Rakyat DUN Tandek 1971-1976. Temu bual di Kampung Talantang 1 pada tahun 2016.

Mohd Ali Kamaruddin \& Jamaie Haji Hamil. (2005). Budaya Politik: Perspektif kepimpinan politik Melayu daripada tradisi kepada kontemporari. Dlm. Maizatul Haizan Mahbob \& Mohamad Zain bin Musa (Ed.). Tinjauan baru politik Malaysia. Bangi: Universiti Kebangsaan Malaysia. 
Mohd Fuad Mat Jali, Ahmad Nidzammuddin Sulaiman \& Zaini Othman. (2005). Pungutan pendapat awam prapilihanraya umum 1999: Satu kajian kes di Kedah. Dlm. Maizatul Haizan Mahbob \& Mohamad Zain bin Musa (Ed.). Tinjauan baru politik Malaysia. Bangi. Universiti Kebangsaan Malaysia.

Milne, R. S. (1973). Patron, client and ethnicity: The case of Sarawak and Sabah in Malaysia. Asian Survey, 13, (10) (October, 1973), 891-907.

Shafie Nor. (1981). Muslihat politik Ghani Gilong. Kuala Lumpur. Hussain Yaakub. No. 2 Pasar Minggu. Jalan Raja Muda Musa. Kampung Bharu.

Sabihah Osman. (2008). Pembangunan politik Sabah: Satu penelusuran sejarah. Jurnal Kinabalu, 14.

Saibon Papalan. 60 tahun. Calon BEBAS Pilihanraya kecil DUN Tandek 1982. Temu bual di Kampung Tingkalanon, Kota Marudu. 13 September 2017.

The New Sabah Times, 14 Ogos 1982.

The New Sabah Times, 15 September 1982.

The Sabah Times, 11 Januari 1983.

Unggas Bodok. 72. Mantan Ketua Pemuda USNO Bahagian Bandau (Kota Marudu) 1972-1976. Kampung Morion. Temu bual 5 Mei 2017.

http://semak.spr.gov.my/spr/laporan/5_Kedudukan Akhir.php 